\title{
Towards field data applications of six-component polarization analysis
}

\section{Other Conference Item}

\section{Author(s):}

Sollberger, David (D); Igel, Heiner; Schmelzbach, Cédric (D); Bernauer, Felix; Yuan, Shihao; Wassermann, Joachim; Gebauer, André; Schreiber, Ulrich; Robertsson, Johan O.A.

Publication date:

2020-05

Permanent link:

https://doi.org/10.3929/ethz-b-000462019

Rights / license:

Creative Commons Attribution 4.0 International

Originally published in:

EGUsphere, https://doi.org/10.5194/egusphere-egu2020-16191 
EGU2020-16191, updated on 13 Jan 2021

https://doi.org/10.5194/egusphere-egu2020-16191

EGU General Assembly 2020

(c) Author(s) 2021. This work is distributed under

the Creative Commons Attribution 4.0 License.

\section{Towards field data applications of six-component polarization analysis}

David Sollberger ${ }^{1}$, Heiner Igel $^{2}$, Cedric Schmelzbach ${ }^{1}$, Felix Bernauer ${ }^{2}$, Shihao Yuan ${ }^{2}$, Joachim Wassermann ${ }^{2}$, André Gebauer ${ }^{3}$, Ulrich Schreiber ${ }^{3}$, and Johan Robertsson ${ }^{1}$

${ }^{1}$ ETH Zürich, Institute of Geophysics, Zürich, Switzerland (david.sollberger@erdw.ethz.ch)

${ }^{2}$ LMU München, Munich, Germany

${ }^{3}$ TUM, Munich, Germany

The analysis of the relative amplitudes of a passing seismic wave recorded on a single seismometer measuring six degrees of freedom of ground motion (translation and rotation) theoretically allows one to extract information on the wave that can conventionally only be obtained from receiver arrays. In the past, it has been shown on numerical data that the extension of conventional three-component (3C) polarization analysis techniques to six-components, allows one to unambiguously identify the wave type of a passing wave and characterise it in terms of its propagation direction (without the $180^{\circ}$ ambiguity inherent in $3 \mathrm{C}$ data) and local wave speed. Additionally, due to the increase in the dimensionality of the data, two waves arriving at a station at the same time can be simultaneously characterised under ideal conditions (low noise).

Attempts to apply such 6-C polarization analysis techniques to field data have so far been met with limited success. Varying noise levels on the individual components and complex wavefields (with more than two interfering waves arriving at the station at the same time) usually prevent the stable recovery of wave parameters using single-station $6-C$ polarization analysis.

Here we discuss first attempts to overcome these issues. We (1) test the robustness of different wave parameter estimators (maximum likelihood, MUSIC) towards high levels of noise and (2) we try to reduce the number of interfering events in the analysis window by performing 6-C polarization analysis on time-frequency decomposed seismograms (i.e. spectrograms) using the $\mathrm{S}$ transform.

The new techniques are extensively tested on field data recorded on the high-performance ROMY ringlaser. 